folk/ed. Derg, 2020; 26(4):859-882

DOI: $10.22559 /$ folklor.1403

\title{
Kültürlerarası Edebiyat Kuramı Bağlamında Taner Baybars Şiiri
}

\author{
Taner Baybars Poem in the Context of \\ Intercultural Literary Theory
}

\section{Mihrican Aylanç}

$\ddot{O} \mathbf{z}$

Batı dünyasında edebî ürünler ve şahsiyetlerin incelenmesinde oldukça sık kullanılmaya başlanan kültürlerarası edebiyat kuramı, Türkçede çok sınırlı tanıtım yazılarının dışında henüz ele alınmamıştır. Özellikle Avrupa'da 20. Yüzyılın ikinci yarısından sonra başlayıp günümüze kadar hızla yoğunlaşan kültürler arasındaki ilişki ve etkileşimler, edebiyat dünyasında da ilgi görmeye başlamıştır. Bu çalışmada ömrünün uzun yıllarını İngiltere'de ve bir süre de Fransa'da geçirmiş olan Kıbrıslı Türk kökenli, şair Taner Baybars'ın şiirlerindeki kültürlerarası değişim ve etkileşim unsurları, kültürlerarası iletişim sistematiği maddelerinden yararlanılarak ele alınmıştır. Metinsel içerik analizine gidilerek Taner Baybars'ın şiirlerinde kültürlerarası etkileşim ve değişimin, şairin poetikasının temel unsurları olduğu ortaya konulmuş; çokkültürlü ve çok dilli birikimin zengin verilerinden yararlanan şairin, yerli/ulusal odaklardan evrensel boyutlara ulaşmayı başardığı sonucuna varılmıştır.

Anahtar sözcükler: kültürlerarası edebiyat, Taner Baybars, kültürel etkileşim, kültür, çokdillilik

Geliş tarihi (Received): 11.03.2020- Kabul tarihi (Accepted): 19.09.2020

* Yrd.Doç.Dr., Uluslararası Kıbrıs Üniversitesi Fen-Edebiyat Fakültesi TDE Bölümü. maylanc@ciu.edu.tr. ORCID 0000-0002-0524-8131 


\begin{abstract}
Intercultural literature research is common in the study of literary works in Europe. However, this method has not been applied yet, except for very limited presentation text, in Turkey. In Europe, especially starting from the second half of the 20th century, interest in the relations and interactions between cultures has intensified rapidly in the world of literature. In this work, the elements of intercultural exchange and interaction in the poetry of the Turkish Cypriot poet Taner Baybars are discussed using the materials of intercultural communication theory. As a result of textual content analysis and descriptive studies in Taner Baybars' poetry, intercultural interactions and changes to be fundamental elements of the poet's poetica are shown. It has been concluded that Taner Baybars, who had been nourishimg from the rich data of multicultural and multilingual accretion, had succeeded in reaching universal levels from local/national foci.
\end{abstract}

Keywords: interculturel literature, Taner Baybars, culture, multilingualism

\title{
Extended summary
}

Taner Baybars (1936-2010) was a poet who was born in Cyprus and lived on the island in his early youth during which he received education, acquired the culture and gained life experiences on the island. Later, he moved to England and then to France, the effects of multiculturalism and multilingualism is reflected in his works. This article is the study of the poetic character and poems of Baybars. Besides writing poetry, he was also a painter with numerous paintings. In this article, the cross cultural elements that give personality and identity to his works will be identified and studied. Intercultural research has observably became widespread, Taner Baybars' works reflect the effects of different cultures on his poems and is also worthy of a praise for the comprehensive methodology applied in his work. As a fact, language is one of the most important tools in reflecting the cultural characteristics and accumulations of a society, Taner Baybars, who wrote his poems in three different languages occupies a position at the center of the theory in question. Learning another language and the use of natural tools of everyday life reveals new shifts and changes for the identity of the individual.

The method of analysis employed on the literary works in this study is cross cultural analysis method. Three subtitles of declarative knowledge (savoir) are based on; the theory of world view (culture générale), sociocultural knowledge (savoirsocioculturel) and intercultural awareness (prize de conscienceinterculturelle) theories helped to facilitate the history and principles defined for cross cultural theory used in this study, and has been used to examine the poems.

Interculturalism questions the unchallenged norms and dogmas by challengeing the reflections of foreign spaces and data in individuals.

The bridges created by interculturalism can turn differences between states, languages and even continents can turn into common / similar or changeable new phenomena . 
Intercultural theory defines the changes and interaction. However, the concept of crosscultural literature with its semantic unity centers on a new and different literary discourse instead of including literature on migration, refugees and literature relating to home sickness.

The change of borders or the formation of individual borders, intercultural literature research offers new approaches in cultural differences, partnerships and identity formation processes. In the intercultural literatury studies basically adresses the concept of multiculturalism.

Born in Cyprus, Taner Baybars immigrated to England at a young age, lived there for many years and then passed away in France, where he had immigrated. Constructing his verses, prose, pictures as well as his poetry with a knowledge distilled from different cultures extending from the native Cypriot to the British and the land of Franks. He applied his multilingual and multicultural experience to his works. There are limited studies on the works and poetry of Baybars, who migrated to England after writing his first book at the age of 18 and transitioned to a colonial subject . Mehmet Yaşın carried out the primary and important studies about Taner Baybars, describes the poet as a cosmopolitan with roots.

The following systematic has been applied in the examination of the poems of Taner Baybars in terms of interculturality:

In examining the reflections of the multiculturalism in poetry that this new artist identity revealed;

A- Cultural conflicts and cultural encounters in the content of the texts:

1. Symbols,

2. Heroes,

3. Rituals and values (Kartar1, 2001).

B- In structure:

1. Types of adaptations,

2. Language diversity,

3.Intertextuality and

4. Hybridity as the basic criteria (Mecklenburg 2008: 15).

Two basic binaries in the intercultural literary approaches; are cultural conflicts and encounters. Without entering the details of geography-centered (géo-littéraire) data, text analysis reveals that cultural encounters and conflicts constitute the general texture of Baybar's poetry when the poetry is thoroughly examined. The pominent differences that shape the basis of cultural encounters and conflicts are symbols, heroes, rituals and values Rituals and values have helped us to understand Baybars' process of interaction and acculturation that we mentioned earlier. Examples of genre adaptations (Mecklenburg, 2008: 15) are also encountered in the formal examination of Baybars poetry with a focus on intercultural literature.

Intercultural literary studies is a sub-discipline of comparative literary studies. It provides opportunities to reach concrete evaluations and results by revealing the multidimensional relations and interactions in the reception and assimilation of literary works.. The theory, can 
create bridges between generations, nations and geographies, as data in different focal points are handled; Concrete benefits can be obtained from the examination of literary works and personalities that are shaped through the relationships, contradictions and interactions between cultures.

Intercultural literature is in an effort to bring the subtleties of understanding and sharing to the agenda in the chaotic structure of the earth. by studying the reflections of religion, language and inter-civilizations dialogues on literary products, and the by analyzing the concept of "the other". Authors to be studied in this respect must have assimilated the multicultural atmosphere and reflected their knowledge in their works. Data analysis ranging from mythology, history, anthropology, sociology, psychology to linguistics of the work and determining the characteristics of the multicultural literary product fort he processes of such transfers.

In this research, cultural conflicts and cultural encounters in terms of content; In the formal sense, genre adaptations, language diversity, intertextuality and hybridity were examined with a methodical application on Taner Baybars' poems. There is limited research on the Works of Taner Baybars, who as a poet, shaped the poetic structure of Turkish with extensive expressions of English and French while diversifying the process of acculturation in the Middle East and the Mediterranean in Britain and France. Taner Baybars whose culture is based on the Middle East-Mediterranean culture; and as a poet who later absorbed the Anglo-Saxon culture, is on path of development from local to universal.

In this study, the Turkish translations of Baybars' poems, most of which are in English and some of them in French, were used and this creates the limitations of not being able to reach original texts. However, the fact that these translations of the poems were made by poets (such as Mehmet Yaşın, Gür Genç Korkmazel) or by himself, with the contributions of an artist, provided a relative solution in the research process.

In the early poems of Baybars, the geographical disperison of the works portray the local cultures which range from Famagusta to Üsküdar and to Istanbul . It fins representation with images such as the henna fingers in Cypre in the poem entitled Gülten, the satin of Cypres, the migration of the poet at a young age, and the new geography reflects the initial steps of the poet's method by including cultural conflicts and encounters. Although the cosmopolitan structure is mentioned, the transition from Cyprus, which has the typical features of the Mediterranean culture to the UK-centered western culture, followed by the French experience of the poet expands the dimensions of the mentioned conflicts and encounters. Symbols, heroes, rituals and values that shape the basis of cultural conflict reveal the new character of Baybars's poetry. The triple structure in the language, the cultural richness of data belonging to these languages, created the original structure in the expression focal points of Baybars's poetry. The fact that the years the poet lived coincided with the periods of intensified cultural transitions across Europe influenced the richness of multicultural metaphors and images, intertextuality, connotative, close and distant associations in his poetry. Taner Baybars, standing at the center of a wide range of interaction ranging from mythological data, ancient and contemporary literature to influential names / works of the art world, scientists, holy people and values, enabled the poet to convey different cultural elements to his lines in the routine wheels of daily life. 
Baybars has manifested the identity of a universal "poet of the world" without ignoring the humanistic point of view and employing the rich themes and competent expressions in his poetry and filtered by the culture of the geographies where history of humanity has been shaped.

\section{Giriş}

Baybars, belirgin ve açık seçiktir. Anlam katmanları ile mecaz ve imgeler arasinda sessizliği nasil kullanacağın iyi bilir.

Terry Eagleton ${ }^{1}$

Türk Edebiyatında henüz sınırlı örneklerini gördüğümüz kültürlerarası edebiyat araştırmaları, Batı dünyasında özellikle 20. Yüzyıl'ın ürünü olan kültürel çeşitlilik ve farklılıkların önem kazanmasıyla yaygın bir biçimde ele alınmaya başlanmıştır. Bu yaklaşım, özellikle çoklu kültür katmanlarının bulunduğu coğrafyaların ya da çokkültürlülüğü bireysel olarak yaşamış sanatçıların yaratılarındaki yapının çözümlenmesinde, edebiyat araştırmaları açısından yeni ufuklar açmıştır. Bireysel ve toplumsal entegrasyonların farklı kültürler içindeki konumları çeşitli oluşumlarla ortaya çıkmaktadır. "Yabancı" ve "yerli” birbirlerine muhalif konumdaki varoluşlarına rağmen zaman ve mekân içinde, "muhalifliğin" ötelendiği, etkileşim ve paylaşım ortamlarının oluştuğu gözlemlenmektedir. Kültürlerarası edebiyat bu temel yaklaşımla hem metinsel düzeyde hem de sosyo-kültürel bağlam açısından önem kazanmaktadır (Von Zimmerman, 2006: 8). Hâkim kültür, ön kabulünü bertaraf ederek kültürleri bütünleştiren bir yapılanmayı gündeme getirmektedir.

Kültürlerarası terimi, değişim ve etkileşimi sembolize eder. Ancak kültürlerarası edebiyat kavramının anlam alanında klasik göç, sığınma arayışı, ülke özlemi gibi kültürel deneyimlerin aktarılmasının yerine, yeni ve farklı bir edebî söylemin varlığı söz konusudur. Sınırların değişmesi ya da bireysel açıdan sınırsızlıkların (sınır ötesinin) oluşmasıyla birlikte kültürlerarası edebiyat araştırmaları kültürel farklılıklar, ortaklıklar ve kimlik oluşumu süreçlerinde yeni yaklaşımlar sunmaktadır. Burada kilit nokta, değişimin birden fazla yüzeyde gerçekleşmesi ve kimliğin oluşumuyla ilgili içgörünün (insight) ortaya çıkmasıdır. Sanatçıların yapıtlarına yansıyan kültürel kalıpların analizi, kültürlerarası izleklerin analiziyle çatışma ve çözümlemelerde yeni bakış açıları getirmektedir.

\section{Tarihsel süreçte kültürlerarası edebiyat kuramına genel bir bakış}

Kültürlerarası edebiyat teriminin irdelenmesinde temelde çokkültürlülük kavramından yola çıkılabilir. Kuramcılar, bir yandan "çokkültürlülük, çağdaş dünyada yaşamsal her şeye, birbirinden büyük oranda farklı olan insanların birbiriyle etkileşim içinde olduklarına ve birbirleriyle iş yapmaları gerektiğine işaret eder" görüşünü sunarken, diğer taraftan "bir toplumdaki bireylerin kendi kültürlerinin dışındaki verilerle iç içe olmalarının da toplumsal çokkültürlülüğü yarattığı” fikrini ortaya koymaktadırlar (Bozkurt, 2002). 
Kültürlerarası iletişim terimini ilk kez kullanan ABD'li antropolog Ruth Benedict, Krizantem ve Kılıç (1966) adlı eserinde Japon toplumunu antropolojik yöntemlerle ele alarak sonraki çalışmalara önemli bir zemin hazırlamıştır. İlerleyen yıllarda özellikle Avrupa'da kültürlerarası geçişkenliklerin çalışma hayatı, siyasal olgular gibi etmenlerle bireysel ve kitlesel göç hareketlerine yol açmasıyla her toplumda ortaya çıkan “öteki”nin konumu, kültürel çeşitliliği merkeze alan çok bileşenli yeni bir bakış açısını ve buna bağlı olarak kültürlerarasılığı yaratmıştır. Özellikle iletişimde önem kazanan kültürlerarasılık, giderek farklı alanlarda yeni bakış açılarının, yöntemlerin doğmasını sağlamıştır. Kültürlerarası iletişimin tarihsel gelişimi, ana damarda sosyal bilimlerin epistemik çizgisini sürdürürken bu temel yapısıyla kültürlerarası edebiyata da önemli yöntembilimsel katkılar devretmiştir.

Antik Uzak ve Yakın Doğu edebiyatlarının bireysel ürünlerinin zaman içinde sistematikyapısal varlıklarının estetik, ideolojik bağlamda -tür ve biçimlerde- metamorfozlara uğraması, kültürlerarası edebiyat ürünlerinin ortaya çıkmasını sağlamıştır. Bunun sonucunda II. ve VIII. Yüzyıllar arasında Çin Sincan/Türkistan ana merkezli ortak edebiyatın İpek Yolu boyunca Pamir, Semerkand, Buhara, Merv, Palmira rotasını izleyerek Tarsus-Antakya, İskenderiye ve Roma'ya ulaşıp Bizans'ta olgunlaşması, dört büyük evrensel kültürle (Avrupa Greko-Roman, Oryantal (Doğu) Batı, Güney ve Doğu Asya) kaynaşması, entellektüel bir gelişim yaratmış; kültürlerarasılık ve kültürlerarası edebiyat alanlarının oluşturulmasını sağlamıştır. Antik Yunan ve Hint geleneği ortak estetik sembolleri (interartistic symbiosis) yaratırken dinsel bağlamda Budist-Manihaizm-Nestoryen merkezli "géo-littéraire” edebiyat, mitik Babil Kulesi ile taçlandırılmış olan Sankritçe'ye dayalı kültürlerarasılığın edebî kimlikli başyapıtlarını ortaya koymuştur. Çin, Uzak Doğu, Okyanus çevresi, Himalayalar ve Tiyanşan'ın engin topraklarında tohumlanmış özgür ruh, kültürlerarası hoşgörü ve anlayış, Batıya seyahatini sürdürürken kültürü taşıyan, paylaştıran artık insanlar ve ulaşım araçları değil, yaklaşık altı bin dille kurgulanmış, beş bin yıllık maziye sahip edebiyat olmuştur (Galik, 2000: 4).

Bu durum Asya ve Afrika' da yeni edebiyatlar yaratırken Euro-Amerikan dünyası IX. ve XX. Yüzyıllar boyunca bu etkilenmeden uzak duramamıştır. Antik öncesi (pre-antic) ürünlerdeki genetik-iletişim işleyişi, daha sonraki zamanlardan kuşkusuz farklıdır. (Berdnikov,1989; Galik'ten). Ancak onlarda bulunan yapısal özellikleri irdelemeden daha sonraki dönemlerin olgun, yetkin örneklerini bile anlamakta güçlük çekilebilir. Avrupa ülkelerinde sömürgeci yapıların giderek ulus devlet kimliğine bürünmesi, iş gücü talebi, siyasal olayların doğurduğu devinimler "öteki”ni yeniden gündeme getirmiştir. Evrenselliği temel paradigmaları arasında kabullenen Batı kültürü, “yerel”e ve “ötekisi”ne gözlerini çevirdiğinde kültürlerarasılık ve bu bağlamda kültürlerarası edebiyat, temel ilke ve uygulamalarıyla Avrupa entellektüalizminde yerini almıştır.

Kültürlerarası araştırmanın sosyal, antropolojik ve psikolojik bilimlerde yaygın kullanılan bir metodoloji olması, kültürlerarası edebiyat araştırmalarını da önemli kılmaktadır (Gallagher ve Savage, 2012:1). Kültürlerarası edebiyat kuramının Rus ve Çek yapısalcıların temel paradigmaları kökeninde Orta Avrupa'da ortaya çıktığı varsayılır. Rene Wellek'in 1959 tarihli Karşılaştırmalı Edebiyatın Krizleri adlı çalışmasında vurguladığı "edebiyat bilimcileri, bireyin edebiyat dışı varoluşu ve varlık süreçlerini dışladıkları sürece hiçbir ge- 
lişim gösteremeyecekleri” yolundaki görüşünün kültürlerarası edebiyat araştırmalarını da gündeme getirdiği ileri sürülmektedir (Wellek, 1963; Galik 2000’den). Dionyz Durisin, 1989 tarihli Theory of Interliterary Process adlı çalışmasında kültürlerarası edebiyatın, karşılaştırmalı edebiyattan farklı bakış açılarını epistemolojik açıdan ortaya koyar (Galik 2). Kuramın paradigmalarında, ontolojik açıdan karşılaştırmalı edebiyatla koşutluk söz konusuyken, epistemolojik çerçevede ayrıldıkları dikkat çeker. Kültürlerarası edebiyat, karşılaştırmalı edebiyatın yöntemlerinden farklı olarak örtülü süreçsel karakter analizleri (implicit processual character) ile etnik alanda ilgili edebî gerçekleri içeren zamansal ve mekânsal değişimleri öngörmektedir. Kültürlerarası edebiyat, alanın araştırma süreçlerinde genetik-temas ilişkilerine dair fenomenleri saptama bakımından dikkat çekici bir konuma sahiptir (Galik 3).

Bu temel paradigmalar doğrultusunda alanın Türkiye'deki ilk kuramsal çalışmalarından birinde kültür ve edebiyat ilişkilerine değinilerek toplumlararası ilişkilerin edebiyata yansıması üzerinde durulur:

Farklı kültürlerin kırılgan bir temas içerisinde bir arada yaşadı̆̆ imparatorlukların heterojen bir kimliğe sahip edebiyatı, kültürlerarası edebiyat araştırmaları için bulunmaz bir hazinedir; çünkü kültürlerarasılık olgusu tam da böyle bir edebiyata yani farklı ama iç içe, birbirine benzemeyen ama birbirinden etkilenmiş olana vurgu yapar. Toplumlararası kültürel temaslar ister dostane iletişim şeklinde ister çatışma boyutunda olsun her şekilde edebiyatta yankı bulur; çünkü edebiyat toplumun bütün dinamikleriyle yansıd $\breve{g}$ l bir alan$\operatorname{dir}$ (Cengiz, 2014: 53).

Bu anlayış kapsamında üreten sanatçı açısından farklı coğrafyaların çokkültürlü katmanlarının sermaye olduğu zihinsel ve duygusal birikimler, yereli hatta bir noktada bireyseli aşarak evrenseli yakalamada, onunla koşut olmada yeni firsatlar doğurabilmektedir. Türk edebiyatı kapsamında kültürlerarasılık bağlamında hemen akla gelen Almanya'da yaşayan Türk kökenli sanatçılara, Avrupa'nın diğer ülkelerinde yaşayanlar da hızla eklenmektedir. Almanya'da Türk-Alman edebiyatı adıyla da sunulan bu oluşumun önde gelen isimleri arasında Alev Tekinay, Emine Sevgi Özdamar, Feridun Zaimoğlu, Aras Ören, Saliha Scheinhardt gibi yazarlar dikkat çekerken (Cengiz, 55) Demir Özlü, İskandinav kültürü içinde olgun eserler üretmiştir.

Kültürlerarasılık, emperyal süreçlerde egemenlik/hegemonya amaçlarıyla ortaya çıkmışken günümüz koşullarında kültürel ortaklıkların oluşmasında farklı kültürlerin kaynaşarak ortak enerji üretmesini sağlamaktadır. Kültürel kodların zengin boyutlarıyla edebî ürünlere yansıması ise, sözsel dinamizmin evrensel kaynaklarını yaratmaktadır. Kültürel özcülükle bağlantısız bir edebiyatın varlığını Türk Edebiyatı çerçevesinde tartışan Laurent Mignon, kültürlerarası edebiyat araştırmaları bağlamındaki farklı yönelimleri, yerli ve yabancı kaynakların irdelenmesi ve örneklendirilmesiyle ortaya koymuştur (Mignon, 2009).

Bu çalışmada, ilk dönem eserlerinde Kıbrıs Türk edebiyatı mensubiyetinden İngiltere’ye göçüyle evrensel bir kimliğe kavuşan Taner Baybars şiiri, kültürlerarası edebiyat bağlamında ele alınacaktır. 


\section{Taner Baybars şiirinin kültürlerarası edebiyat bileşenleri}

Farklı kültürlerin damıtılmış verileriyle dizelerini kurgulayan Taner Baybars (19362010), Kıbrıs yerelinden Britanya ve Frenk topraklarına uzanan evrensel yaşam çizgisini, şiirin yanı sıra düz yazı ve resimle de biçimlendirmiş; çok dilli, çokkültürlü bir birikimin estetik örgülerle süregelen 64 yıllık ömrünün çoğunu doğup büyüdüğü toprakların dışında geçirmiştir. Çocukluğunu Kıbrıs'ın Lapta yöresindeki Güzelyalı (Vasilya) köyünde geçiren Baybars'ın hayatındaki değişim ve dönüşümler, Minareliköy ve sonra Lefkoşa'ya taşınmayla tohumlanmaya başlar. O bir köylüdür, bir tarla çocuğudur, ă̆aç çocuğudur. Şimdi kaldırımlarla örülü şehirde büyümesi durmuştur, hayat durmuştur (Aylanç, 2011: 290). Kentteki eğitim süreciyle birlikte tarla çocuğu ă̆ır ă̆ır değişir (Aylanç, 2011: 294). İngilizce yaşamına girer, şiiri keşfeder, İstanbul aksanıyla konuşmaya başlar. Bu şekilde ikili bir kişilik geliştirir (Aylanç, 2011: 294). Çocukluk dönemlerindeki çokkültürlü ortam, Baybars'ın gelecekteki yaşama bakışını biçimlendiren özelliklere sahiptir:

Baybars spent his childhood always in mixed villages: Vassilia is referred to as a mixed village with its own Greek quarter (Baybars 2005, 15, 24, 37), while Lapithos had a significant Greek community, and also Minareli Köy was inhabited by both Turks and Greeks. Greek "neighbors," fishermen, doctors, wine merchants, or knife sharpeners, are always mentioned as something distant, living close but still not in the same quarter, underlining geographical as well as economic distance (Kappler, 2009).

18 yaşında yazdığı ilk kitabından sonra İngiltere'ye göç ederek kolonyel bir kimliğe geçiş yapan Baybars'ın şiiri, eserleri üzerine yapılan çalışmalar sınırlıdır. ${ }^{1}$ Şair hakkında ilk izlenim/yorumları ortaya koyan Mehmet Yaşın, Kıbrıs’ta Türk dilini işleyen en kuvvetli şairlerden biri olan Baybars'ın felsefi düşünce kaynaklı üslup özelliğinden söz eder (Baybars 1997, 11). Yaşın, Kıbrıslıtürk Şiiri Antolojisi adlı eserinde (anne tarafından ikinci kuzeni olan) Baybars'ın şairlik konusunda hak ettiği yere ulaşamadığını belirtir. Baybars hakkında yabancı edebiyat ve kültür insanlarının yorumlarını aktaran M. Yaşın, şairi kökleri var olan bir kozmopolit olarak niteler. Adada merkez-çevre (metropol-periferi) arasında kalmaktan kaynaklanan öznel iç çatışmaları sonunda, Londra'ya göç eden ve artık İngilizceyi kullanan Baybars'ın bireyciliği ön plana çıkardığını vurgulayan Yaşın, şairin 'ben merkezli' bir şiiri yeğlediğini ileri sürer (M. Yaşın, 2005: 99).

Taner Baybars hakkında yapılmış sınırlı sayıdaki çalışmalarda dikkat çeken ortak görüş; Baybars'ın yerel bir dil ve kültür içinde doğması, "adalı” kimliğine sahip bir gençlik tecrübesi geçirmesi, daha sonra bu kaynağa tümüyle kapılarını kapatarak -çocukluk ve gençlik yıllarından kalan fotoğrafları izlenim/hissetme boyutuna kadar küçültecek- uzun İngiltere yılları ve Fransa eklemli bir ömür sürdürmesi; edebî kimlik ve sanatsal tutumlar bakımından Batılı kaynakların (occidental) etkisinde kalmasıdır (Karahasan, 2004). Bu yönleriyle kültürlerarası edebiyat verileri bağlamında Baybars şiirinin ilginç örneklendirmeler sergilediği söylenebilir. Demiryürek, şairin Kıbrıs Türk kültürü izlerinin görülebildiği Türkçe yazılmış tek kitabı olan Mendilin Ucundakiler'de yer alan şiirlerin Garip akımının etkisinde yazıldığını ileri sürer (Demiryürek, 2016). Dolayısıyla şairin dünyasında yerel Kıbrıs Türk ve 
Müslüman kimlik, mutlak göç (adadan çıktıktan sonra bir daha dönmemiştir) sonucunda benimsediği Avrupa kültürü, İngilizce ve Fransızcanın egemen olduğu dilsel değişim, H1ristiyanlık izlenim ve ilişkileri ile sentezlenmiş/ yer değiştirmiş ve farklı bir kültürel kişilik oluşmasına yol açmıştır.

Bu yeni sanatçı kimliğin ortaya koyduğu çokkültürlülüğün şiirdeki yansımalarının incelenmesinde;

\section{A- Metinlerin içeriğinde kültürel çatışmalar ve kültürel karşılaşmalar:}

\section{Semboller,}

\section{Kahramanlar,}

3. Ritüeller ve değerler (Kartarı, 2001).

\section{B- Biçimsel yapıda:}

\section{Tür adaptasyonları,}

\section{Dil çeşitliliği,}

\section{Metinlerarasılık ve}

4. Melezlik temel ölçütlerdir (Mecklenburg, 2008: 15).

A- Kültürel çatışmalar ve kültürel karşılaşmalar: Karşılaştırmalı edebiyat disiplini, en az iki (edebî) fenomen arasında bir ilişkiyi ve etkileşimleri öngören "karşılaştırmanın" temel metodolojik perspektifini ifade eder (Matajc, 2009:1). Kültürlerarası edebiyat yaklaşımında da temel iki karşıtlık; kültürel çatışma ve karşılaşmalardır. Coğrafya merkezli (géo-littéraire) verilerin ayrıntılarına girilmeksizin şiirin geneline bakıldığında kültürel karşılaşma ve çatışmaların, Baybars şiirinin genel dokusunu oluşturduğu söylenebilir.

Yazarın İngiltere'de yazdığı aşağıdaki satırlarda görülen ruhsal seraplar halinde geçmişe yapılan yolculuklar, yerel kültürün etkilerini vermek bakımından ipucu niteliğindedir:

Klşın mangalda ince külün içine kor halinde odun kömürü gömülü. Bir tarafinda çaydanlık, öteki tarafinda Türk kahvesi için bir cezve. Annem, hep de aşk romanı olan bir kitaptan on ya da yirmi sayfa okurdu. Romanda işlerin iyiye ya da kötüye gittiği her defasında, ateşin çevresinde çömelmiş olan köy kadınları, ya sempatiyle ya da kınayarak başlarını sallarlardı. Kendileri kitaplarda basılı olanlardan çok daha ilginç hikâyeler anlatabilecekleri halde, onlara, bütün bunlar gerçekleşmiş gibi geliyordu herhalde. Yine de, eğitimli bir kadın tarafindan okunan basılı sözün büyüsü, onlarl vecde getirirdi. Annem çok kurnazdı; okumayl, heyecanlı bir bölümün sonunda bırakırdı (Baybars, 1997: 22-23).

Baybars'ın ada yerelliğinin yansıtıldığı ilk şiirlerinde bile tarihsellikle beslenen bütünlüklü bir kozmopolitan yapıyı imlemesi, onun ilerleyen dönemde varacağı noktayı gösteren bir tablodur. Ortak dil ve coğrafî yakınlığa bağlı Türkiye kaynaklı kültür ve sanat alanlarındaki yoğun etki, Baybars’ta sınırlı bir biçimde görülür. Kültürlerarası çatışmanın farklı ve karmaşık dinamizmi hayatı seziş, duyuş ve özümleyiş açısından karmaşık ve sürekli değişen sonuçlar ortaya çıkarır. Adadaki yerel kültürün farklılıklar içinde tohumlanmış bir boyutunu 
sergileyen yapısı, Baybars'ın erken dönem şiirlerine olduğu gibi yansır. Bir Rumeli türküsü olan Alişimin Kaşları Kara türküsünü;

Ve sen,

'Alişimin Gözleri Kara'

Türküsünü mırıldanarak

Odun dumanindan ă̆la

Gam ile değil, tasayla değil

Bu sonsuz bir ip çamaşırcı kadın

Hepimizi sen yıkamışsın

Akıtarak yavaş-yavaş

Damla-damla suyuтиzu.

Gün kısa, gece uzun

Çamaşırlar ipin üstünde

Farkında değiliz insan olduğumuzun... (Baybars, 1954: 21) biçiminde kullanması bu düşüncenin bir kanıtıdır. Pek çok Kıbrıslı Türk’ün gönlünde bir özlem merkezi olan İstanbul, Baybars'in dizelerinde de kendini gösterir:

Bakamam dăglara bakamam

Dağ-dağ olur gözümde hasret

Denizler bu kadar derin

Bu kadar uzak mı Güzel İstanbul

İçinde yanarken gözbebeklerin

Kâtip Üsküdar'da gider

Dudaklarımda Boğaziçi

Mağusa'da sallanan mendiller

Ve her titreyen elde

Seni görmenin sevinci

Dalından düşüyor yaprak

Düşemem ah düşemem

A ̆gaç olamam ki ben insanoğlu

Kuşlar taşısın meyvelerimi

Bahçelerine Istanbul'un (Baybars, 1954: 40-41).

Mağusa'dan Üsküdar'a uzanan mendiller Kâtibim şarkısında dizelere taşınırken mekâna duyulan özlem ve görme sevinci, kuşlarla gönderilen meyvelerle dile getirilir. İlk gençliğini yaşadığı adasından şairde en çok yer eden unsur, son şiirlerine kadar bolca kullandığı deniz, su ve kuş imgeleridir. Baybars'ın şiirlerinde çocukluk ve ilk gençlik yıllarının yaşandığı ve artık uzaklarda kalmış olan Kıbrıs, sınırlı dokunuşlarla yansıtılır. Neşe Yaşın’ın deyişiyle; 
Taner Baybars' '̇n Kıbrıs'ta geçen Müslüman çocukluğu-dinsel bir kimlikten öte kültürel bir kimliktir bu-sonralarl farklı dinler ve kültürlere duyduğu ilgiyle zenginleşir. Sünnet deneyimini anlattığl şiirine çan kuleleri karışır. Uzak bir ülkeye dönüşen anayurdu Kıbrıs, zaten bir kimlik bunalımı mekânıdır. Kendini içine doğulmuş, verili, dayatılmış kimliklerden azade eden Baybars, bu üniformalarl giymese bile onların deneyimlerini ve zenginliğini ekler kendine... Şiirlerini şaşırtıcı, az bulunur bir melez imgeler cennetine dönüştürür (N. Yaşın, 2017).

Daha sonraki yıllarda ana yurtla ilgili şairin bilince yerleşmiş sınırlı örneklerden biri; O’nun babasına yazdığı Memlekete Mektup başlıklı şiirindeki dizelerdir:

(...)

Memleket hasreti?

Hayır, çünkü bir memleketim olmadı hiçbir zaman benim

ama sen değilsin bunun suçlusu

Yine de, deniz ile dă̆ birarada anımsıyorum

geceleyin birbirinden sonsuz uzaklaşan

ama ikisi arasında sallanan beşiğimi (Baybars, 2007: 37).

İngiltere’ye göç sonrası yeni kültürlerin etkisindeki şiirlerinde çevreyi bireysel bir bakış açısıyla yorumlayan Baybars'ın yıllar sonra ilk kez Kıbrıs'ı çocukluk sevgilisi Gülten'e (Gül) yazdığı şiirine yerleştirirken de özünde günceli betimlediği gözlemlenir:

\section{$(\ldots)$}

Bronzlaşan ten, güneşin tende kiraladı̆̆ yazlık

hatırlatır bana Cypre'yi hatırlatır bana, o kınalı parmaklar

okul bahçesinde, selvi kozalakları vardı hani

ve gül'dün sen, iplikleri belleğin- örneği bulunmayan

Cypres sateni, mekik dokuyan şifreyi çözüyorum

düğ̈̈mleri, teyellenmiş kenarlarını senin çıkrı̆̆ında (2007:133).

Taner Baybars'ın şiirlerindeki kültürel karşılaşma ve çatışmaların ikinci basamağı İngiltere'dir. Yeni bir ortamda, farklı bir dilin önce iletişimsel sonra sanatsal üretimindeki sarsıntıları, şairin yeni kimlik verileridir. Böylece yeni bir dille karşı karşıya gelen birey, aslında kendi kültürünün dışındaki bir başka kültürü de kabul etmeye hazır olmaktadır (Roche, 2001:16). Bu görüşe koşut olarak sanatçının kendi diline karşı sorgulayıcı bir tavır edindiği ileri sürülür:

Bu süreç içinde birey kendi diline tam olarak hâkim değilse, yani dilini iyi bilmiyorsa, öncelikle ikinci dili öğrenme aşamasında zorlanır. İki dil arasında bitip tükenmeyen nedensiz karşılaştırmalar yaparak, öğrenmeye çalıştı̆̆l yapılar arasında kurmayı denediği neden sonuç ilişkileri aracılı̆̆lyla-kendince- anlamlı bir sonuca ulaşmaya çalışır. Bu çabanın doğal bir uzantısı olarak bireyde kendi diline, tarihine ve kültürüne karşı sorgulama süreci başlar (Çakır 77). 
Yeni dilin temel olduğu yeni kültür odağı ve kültür verileri, şairin dizelerinde önce Britanya sonra Avrupa odaklı olarak özgürce boy gösterir. Kentteki geniş bulvarlar, Thames üzerindeki köprü ayaklarında oluşan dalgacıkların sergilediği balayı, nehre sineden düşen uzun kurdela, siste, yağmurda parlayan Westminster'in çan kuleleri, Trodos'un, Beşparmakların, Akdeniz'in yerini alır, yağmurda ıslanan kilise çanları, bilinçaltında bir buğday ya da yulaf tanesinin parlayışını anımsatır:

Geniş caddeler üstünde parlldyor sis

Thames nehri bir sineden düşen uzun bir kurdela.

Köprü ayaklarındaki dalgacıklar balayında,

ya koltuk değnekli bir kötürüm gibi

topallıyor dalgacıklar üstünde (...)

Curzon Sokağı'nda güzel bir icattır günah

ve erdemlilik parllyor Westminster'in çan kulesinde,

siste, yă̆murda

bir buğday ya da yulaf tanesinin parladı̆̆ gibi. (Baybars, 2007: 30).

Aynı şiirde bu iki boyutlu duygu evreninin merkezi de boğuk sedalı kilise çanları gibi, dizelerin arasından çınlar;

Adsız bir çanın çaldığını duymaktayım:

London, London, London (30).

Dizelerin devamında kültürel çatışma ve karşılaşmanın teşhisi ilân edilir:

Duvarlar nefesini tutar, ağaçlar gıcırdar

çıplak bir dakika şaşılacak şeyler doğurur;

benim kıllı göğsüm, fazlasıyla uzamış tırnaklarım

ve trafĭgin nă̆mesiz gürültüsü (31).

İngiltere'deki ilk yılların sarsıcı, sarsıntılı dönemlerinden sonra benzer göç olguları sonucu bireyde meydana gelen değişimlerin seyri evrensel bir düzleme taşınır.

Birey yaptı̆̆ karşılaştırmalardan usanıp, kendini tamamen öğrendiği ikinci dile (kendini onu konuşan topluma adayarak) verir. Karşılaştığı her bir yeni olguyu ki bu bazen tek bir sözcük bile olabilir, hayranlıkla karşılar ve bundan nedensiz zevk alır. Hatta karşılaştığı her yeni olgu, onun için mutlak bir ideal olarak vazgeçilmez bir anlam kazanır. Süreç bireyin kültür ve kimlik çatışmasına kadar uzanabilir (Roche, 2001: 37).

Ömrünün sonuna doğru Fransa'da iken ana diline dönerek Türkçe yazdığı Kaybolmuş Kardeşler...Ben? başlıklı şirinde şairin bilinçaltında saklı duran Kıbrıs ve Kıbrıslılığının diğer kültürler arasındaki gel-gitlerinin izdüşümü resmedilir: 
Evet...kayboldum, işte öyle, çok pek çok zaman geçti,

Uzak ülke o, uzak düşlerden daha uzak doğduğum yer,

isimler, resimler, hatıra-satıra, kahve fincanında geleceğim:

Klş duvarında evimin açılmaz yaz panjurları?

Vasilya'daki tavuk kümesinin kokularl geliyor burnuma... ...

Hatırlyyorum çoğunu ben, berrak gözleriyle baklyorlar bana..

O dillerde olmayan şehitler, ıssız köylerin nemli okullarında

Şehit olmak yanız tüfek ateşiyle değil, mitralyözle değil, değil...

(Baybars, 2007: 250) dizeleri, ana yurdunda geçirdiği çocukluğunun ve acılı tarihin Baybars'ın benliğine yerleşmiş olgular olduğunu ve bu olgulardan kaçamadığını somutlar. Valras-Plage (Güney Fransa) şiirinde çocukluğunu geçirdiği Vasilya/ Güzelyalı (Kıbrıs) imajı zihninde Arap bir kadının yüreğindeki yurt hasretiyle depreşirken çan sesleriyle feryada dönüşür:

Uyku çapakla sıvamış kirpiklerimi, göremiyorum.

Haa, açıldılar; Vasilya değil burası, ak'ını yitirmiş deniz,...

Çan sesleri, gemi direklerine çarpan halatların feryadı

( ...)

Turuncu bir kubbe gibi çömelmiş bir Arap kadını

Yurt hasretiyle basıyor bağrına gamzeli küçük kızını. (2007: 251).

$\mathrm{Bu}$ süreçte kültürel karşılaşma ve çatışmaların temelini biçimlendiren farklılıklar ise semboller, kahramanlar, ritüeller ve değerlerdir (Kartarı, 2006: 4).

1. Semboller: Şiirde simge kullanımına ağırlık vermiş olan Baybars, kültürel çatışma ve karşılaşma kapsamı içinde yakın ve uzak çağrışımlar, yan anlamlar yoluyla ve genelde özel adları kullanarak çok katmanlı bir şiir dili yaratır. Kolomb’un Dönüşü şiiri, kâşif Kolomb ve adamlarının hissettiği umut, umutsuzluk, yaşam tutkusu; kimi zaman da an'ların ne denli değerli olduğuna dair hislenmelerine bağlı sembollerle örülüdür. Şairin yaşama bakış açısını simgeleyen şiiri ise, Kutsal Kitaplar'dır. Başlığın çağrışım alanına tezat oluşturacak biçimde bir yandan kutsallığın kaynaklarına göndermeler yapılırken şiirin devamında Darwin, Karl Marx, Freud ve Einstein gibi bilim insanlarının yapıt ve düşünceleri birleştirilerek bir tür öznel, düşünsel bileşime varılır:

Ilk modern sapma bilirim Darwin'i, kopuş

çă̆daş gerçeğe doğru.

Toplumsal şafağında onun, Karl Marx belirir,

sonra karmakarışık bir aklı çözüp düzelten Freud. 
Kımıldar parmaklarım ve Einstein'la karşılaşırım,

elinde kemanı, evrensel bir notayı çalan,

samanyollarını ölçerek her ince telde. (Baybars, 2007: 65).

Baybars'ın şiirinde sembol kullanımı alışkanlı̆̆ını yansıtacak somut örnek, O'nun Centaurus 'ta Gül Paskalyası adlı şiiridir. Centaurus burcundan (takımyıldız) yola çıkan şair, dilin anlatım gücünden yararlanarak güneşe en yakın gezegen Alpha Centauri'ye, Jung-Fu heksagramına, Hıristiyanlığın temel taşlarından Saint-Augustine ile Saint Paul'e uzanırken, kuantum fiziğinin öncü isimlerinden Niels Bohr'u dizelerine farklı sembolik anlamlar içinde yerleştirir. Şiirin sonu da Yunan alfabesinin ilk ve sonuncu harfleriyle kurgulanır, böylelikle yaşam ve ölüm sembolize edilir:

Geri gelsin diye kaybolan, kazandı̆̆ım uzay yılları, koyar

beni ön kesesine,

nerede biterse bitsin yolumuz, ne yaşta, ne çıkar? Biziz Alfa ve Omega (2007: 233).

Göksel varlıklarla ilgili sembolik metaforlar Baybars şiirinin süreklilik gösteren özelliklerinden biridir. Süratle Kaçan Işı̆̆ı̆ Sesi şiirinde Kara Delik kaosun sonsuzluğunu simgelerken burçlar (Yengeç, İkizler) anlam taşıyıcılıklarıyla Prometheus'u imler. Şairin başka şiirlerinde de yer verdiği Çin'in en eski kitabı sayılan ve Konfüçyüs ile Tao üzerine etkisi olan şiirin dipnotunda vurgulanan I Jing kitabında kandilçiçeklerinin saplarıla yapılan antik remil atma geleneğine göndermeler yapılır. Artemis'in ızdırabı (Söz-Böcek şiiri), Baküs'ün çift yaşam süresi (Tilkiye Dönmüş Baküs), Catullus'un dizelerinin şiirine taşınması, bu kapsamdaki örneklerdir.

2. Kahramanlar: Baybars'ın tarihsel kahramanları Romalılar, Crosoe, Pan, Ianus, Kolomb, Horatius, Romalı şair Catallus gibi evrensel kültürü yoğuran diğer tarihi şahsiyetlerdir. Suyu arayan ağaç kökleri gibi yaşadığı yeni kültürün can damarlarının ardına düşen Baybars, mitoloji -ve tarihi- şiirinde önemli bir kaynak olarak görür: Kır Sarhoşluğu şiirinde eski zamanları sızdıran bir köyün duvarlarında Romalıların yankılanan savaş çığlıklarından söz eder. Kâş̧ifler şiirinde mitolojinin evrensel motifi Pan'ın ölümünü Kutupyıldızlyla birleştirir. Tekin Olmayan Olaylar şiirinde buhranlı bir gecenin acıları içindeyken vücudunun bir tarafının Medusa'ya dönüştüğünden dem vurur. Roma mitolojisinin öne ve arkaya yani gelecek ve geçmişe bakan; eski ve yeni yılın sembolü çift başlı tanrı Ianus, (Şiirin dipnotunda bu tanrının Latin dilindeki January, Janvier biçimleriyle Ocak ayına ad olduğu belirtilir) hem simgesel hem şairin kahramanlarından biri işlevleriyle Noel'in 21. Günü başlıkl seri şiirlerin 17.sinde görülür. Mitolojinin popüler simgelerinden biri olan Kantauros, Ölçüsüz Ayrllk Var Aşk Olmayan Yerde adlı şiirde (122) aşk ve arzu duygularının amaca ulaşmasında vuslat imgesi olarak kullanılır:

Ben yerde, sen yumuşak yastıkların arasinda, yağllyorsun

abanoz karınaltını, bir Kentauros'un beklerken binmesini üstüne (2007: 122). 
Yunan mitolojisinde Thebes'li Apollon'un kör bilgelerinden olan ve yedi y1l müddetle kadına dönüştürülmesiyle ünlü Teiresias, karmaşık ve bunalımlı kişiliğiyle şairin ruh dünyasını aktarmada bir simge olarak kullanılır:

Ah Teiresias, o benimle olmadı̆̆ında O'yum ben,

ben kendimim o benimleyken;

faltaşı gözlerle baktım ona çok defa,

alkolden körleşmiş; umarım hissetmeye devam edeceğim

hünerli sol elinin elim üstündeki seğirmesini. (1995: 158).

Öte yandan Baybars şiirinde görülen kahramanlar albümünün önemli bir bölümünü de filozof, yazar, şair ve müzisyenler oluşturur. Tepelerde Vicdan Azabı şiirinde Vergilius'un Tityus, Amarillis ve Amyntas hakkındaki konuşmasını işler; Horatius'un doğa güzelliklerine, şelalelerine göndermeler yapar. Noelin 21. Günü şiirlerinin 5. sinde Theocritus'un ünlü, ineğin boğaya dönüşüm anekdotunu ironik bir tutumla dizelerine yerleştirir. Filin Hortumundaki Sünger şiirinde Herakleitos'un düşün dünyasının yanı sıra Ezra'yı ve yumuşak yastıkta dinlenen sessiz dilini düşünüyorum dizesiyle hayatının son yıllarını kimseyle konuşmadan geçiren şair Ezra Pound'a gönderme yapar. Pound'un bilinçli suskunluğunun Baybars'ı oldukça etkilediği Ezra'nın Sessizliği şiirinden algılanabilir. Aynı şiirde Diyojen ile İskender'in ünlü diyaloguna da atıf yapılır (118). Edebiyat dünyasından Marcel Marceau (Noel'in 21. Günü, 18), Hemingway ile Goethe ve eseri Faust Tilki Şairler Arasında şiirinde (Baybars, 2007: 205) bir araya gelir. Feylesof Kapısı Önünde başlıklı şiirde Shakespeare'in derin yalnızlığı, Ayasofya ile özdeşleştirilerek yansıtılır. Liszt'den (Sally Ann Hodges şiiri, 252) Kyleie Minogue, Elton John, Stevie Wonder, David Bovie'ye (Baybars, 1997: 158) uzanan bestekârlar, müzisyenler (117) dizelerde görülür. Baybars, Kristof Kolomb’un Yalnızlı̆̆ s şiirinde kendi derin ruhsal yalnızlığını uçsuz bucaksız okyanusta bir umudun ardına düşmüş olan Kolomb'un kaotik kişiliğini irdeleyerek kederini paylaşabilir insan, ama umudunu asla ifadesiyle anlatır. Aynı şiirin ilerleyen dizelerinde Vespucci ve Marco Polo da yeni umutların simgesi olan yeni mekânların kâşifleri ve şairin ruhsal arayışlarındaki engin açılımların sembolü olarak anılır (125).

3. Ritüeller ve değerler: Baybars'ın İngiltere ve Fransa günlerinde Hıristiyan kültür ve sanat verilerine sempati ve yakınlık duyması, dizelerine somut bir biçimde yansımıştır. Köklü bireysel kültürel değişimlerin oluşum ve sonuçlarını irdeleyen bir çalışmada ileri sürülenler, Baybars'ın daha önce değindiğimiz etkileşim ve kültürleşme (acculturation) sürecini anlamamızda yardımcı olabilir:

Bu aşamada, arayış içinde olan birey kültürel farklılıklarını görmezden gelmeye başlar. Kendini dıştan gelen farklı etkilere karşı savunmaktan vazgeçer. Kimi zaman açıklayamasa da karşılaştığ farlılıkları sorgulamadan kabul ederek 'alışılmadık' olana saygı duymaya, olumlu bulduklarını algılamaya, benimsemeye, kendi yaşamında uygulamaya başlar ve sonuçta kendi kültürüne ait olanlardan rahatsı olmaya ve ötekini tercih edecek şekilde özünü dışlamaya varan bir dizi duygusal süreç yaşar (Çakır 78). 
Aslında Kutsal Kitaplar şiirinde gerçeği o kadar uzakta aramamak gerektiğini vurgulayarak ilk modern sapma bilirim Darwin'i kopuş/ çağdaş gerçeğe doğru/ Toplumsal şafağında onun, Karl Marx belirir (Baybars, 2007: 65) derken bilim ve felsefeye öncelik veren Baybars, daha sonraları Romalılarının yankılanan savaş çığlıklarından (26) yola çıkarak kilise, Hıristiyanlık, papazlar, çan kuleleri, paskalya, azizler, gibi odaklarda sprituel bir yönelişin içinde olur. "Noel'in parlaklı̆̆ı, hindi geleneği, Noel kartları, doğrudan bir Sistersiyen Manastırı'nın bulunduğu St. Bernard Dă̆ı başlıklı şiir, farklı şiirlerde Robert, Paul, Patrick adlarını taşıyan pederler, Salve Regina ilâhisi, akşam ayinlerindeki ilahiler (185), Tanrı'ya Doğru Düşlemek şiiri (186), Haç çıkarıp oturdum ve alev alan kilise stralarına baktım/ sevgiyle kurutulmuş çiçekler gibi parlayan gibi dizeler (169) ve benzer unsurlar, değinilen dinsel kimliğin yansımalarıdır. Bu şiirlere yerleşmiş olan dinsel değerlerle ilgili veriler, Hıristiyan inancı sistematiğinde kişinin varlığının kutsal kılınması evresinde gözlerini varlıklardan tekrar Tanrı'ya çevirerek ve Tanrı'nın değerlerine koşut düşünce ve inanışlar kuşanarak kutsal'ı güncele taşıma çabasını göstermektedir (Tidball, 2009: 125). Baybars'ın bu bağlamdaki dizelerde bencillik ve çıkarcılık kavramlarına açık bir karşı duruş sezinlenmesine karşın bu duruşun protest bir tavır yerine insancıl (hümanist) bir tutumla biçimlendiği söylenebilir. Bunun dindarlıktan başka bir şey olduğunu vurgulayan Baybars, Ama tinsel, politik veya çoğu kavram gibi din de bir milletten başka millete veya bir bireyden öteki bireye farklı bir kılığa girer diyerek Maimonides (Musevi), St. Augustine (Hıristiyan) ve İbni Sina'nın (Latin metinlerinde Avicenna- Müslüman) kendi düşünsel birikiminde önemli etkileri olduğunu ifade eder. Ayrıca Yunus Emre'nin insancıl din anlayışı ile Dede Korkut'taki konuya ilişkin mesajların kendi dinsel düşünce oluşumlarında yeri bulunduğunu vurgular (Baybars, 2014: 123-124). Baybars'ın Hıristiyan mistisizmi ile ilişkileri ya da etkileşimi konusundaki bir yorumda ise; Baybars, kendinden beklenmedik bir durum olsa da, ilgi çekici bir tarzda $\mathrm{Hl}$ ristiyan mistisizmine yöneliyor ve bu izlek, ondaki sevginin bir başka boyutunu başarlyla dile getiriyor denilmektedir (Sidwick\& Jackson- Baybars, 1997'den:139). Şairin Munçak Pençesi adlı şiirinde de kendi ilham perisi olduğunu söylediği Çinli Miu merkezinde Hz. İsa'nın semaya yükselişini simgeleyen Yükselme Günü'ne (Ascencion) atıf yapılır:

Miu, sevgilim; annem, dadım; sorarım ona ne gördü benim dışımda, uzay yolları buluştu mu O’nunkiyle, Yükselme Günü'nde? Yok, Miu gitmişti çok daha evvel bir Zaman'a, Yaşam hâlâ bir meram Allah'ın elinde.

(2007: 232).

Bu eğilimin oldukça açık görüldüğü; farklı ritüel ve mistik unsurların bir araya geldiği şiirlerden biri olan Centaurus 'ta Gül Paskalyası (233)'nda, başka bir şiirinde de andığı antik Çin kitabı Il Jing'de bulunan Centaurus (burç, takımyıldızı), Jung Fu adlı heksagram, Hıristiyanlığın en önemli adlarından St. Augustine, Hz. İsa, Saul (St. Paul), Alfa ve Omega gibi sembol ve ritüeller, spirituel bağlamda Hıristiyan inanç ve terminolojisi kullanılarak işlenir (233).

\section{B. Biçimsel anlamda kültürlerarası edebiyat}

1. Tür adaptasyonları: Baybars şiirinin biçimsel anlamda kültürlerarası edebiyat odaklı incelenmesinde tür adaptasyonları (Mecklenburg, 2008:15) örneklerine de rastlanmaktadır. 
Geleneksel Türk şiirinin dörtlük biçimini kullanmayan Baybars, 1951-1953 yılları arasındaki şiirlerini topladığı Mendilin Ucundakiler adlı kitabında değişik şiir biçimleri kullanır. $\mathrm{Bu}$ şiirleri, farklı sayılardaki dizelerden oluşan bentler halinde yapılandıran Baybars, sadece Veresiye başlıklı şiirinde daha sonra örnekleri sık görülen kısa şiir denemeleri yapar:

Bir can aldım veresiye / Ne olur bütün borçlarım gibi, / Bir unutulsa bu da.

(2007: 17).

Zaman Kıranlar (2001; Baybars 2007 içinde) adlı kitabındaki şiirlerinde uzun dizeli biçimsel uygulamalar yapan Baybars, Fransızca yazdığı şiirleri arasında Haiku biçimini de kullanır:

Fizik-Kuantum Haikusu

Kaosta bir kelebek-

ilkbaharda kanatlarımı çırpıyorum

ama sevgilimi öldürüyor firtına

hüzünlü bir sonbahar günü. ( 97 ).

Biçim denemeleri arasında Trajik Bir Illham Perisine Sahte Kaside (2007: 182) adlı şiiri, Osmanlı şiirindeki klasik kaside örgüsündedir.

2. Dil çeşitliliği: Küreselleşen dünyada ulusal kültürlerin ilişkileri konusunda yeni formlar ve içerikler gündeme gelmektedir. Dinler, ideolojiler, demokratik değerlerdeki farklılıklar, toplum içi kültürlerarası diyalogda sorunlar yaratırken çok dillilik bu aşamada önemli çözümler ve seçenekler ortaya koyar (Venera vd. 2016:1).

Baybars ilk dönem ürünlerinde Türkçeyi kullandıktan sonra İngiltere'de yazdığı şiirlerinde İngilizce, daha sonra yerleştiği Fransa'da da Fransızca şiirler yazmıştır. Şiirin başka bir dile çevrilmesinde bile karmaşık sorunların yaşandığı bilinirken Taner Baybars'ın üç farklı dilde şiir üretmesi, dil çeşitliliğinin somut göstergesidir. Şiirin evrensel boyutlarında farklı dillerde ürün veren Baybars, bir yandan o dillerin ayrı anlatım varsıllıklarından yararlanırken diğer yandan da o dillerin renkli kültürel verilerini dizelerine taşır. Üç dilin anlatım olanaklarından hareketle kendi şiir dilini yaratmış olan Baybars, metafor oluşturma, mecaz, yan anlam, uzak çağrışımlar gibi teknikleri doğal bir akış içinde dizelerine yansıtabilmiştir. Yaşadığ yapılan bir röportajda bu konuyla ilgili olarak; Dil dediğimiz, her gün içimize çektiğimiz ve dişarlya verdiğimiz hava gibi bir şeydir. Birisi tamamen Ingilizce bir çevrede yaşayıp da, içine çekip dışarıya verdiği dilden etkilenmekten kaçınabilir. Iç̧inde doğduğu dili artık duymaz olur insan. (...) Benim durumu da, ayrıca Türkçenin değişen doğası sorunu var. Bazı modern metinlerin çok az anlamı var benim için, çünkü bu dil her zaman yeniden yaratılıyor (Baybars, 2014: 119-139) derken dil-şiir dili ilişkisine yönelik görüşlerini ortaya koyar. Baybars'ın çok dilli şiir üreterek İngiltere ve Fransa gibi etkin edebî merkezlerde eleştirmenler tarafından saygın/takdirkâr bir biçimde yorumlanması dikkat çekicidir:

Şiirlerini bir ikinci dilde yazmanın güçlükleri, Taner Baybars’1 mevcut şiir gruplarının baskı ve etkisinden çıkarıp, çağdaşı olan Britanyalı şairler karşı- 
sında avantajlı duruma getirdi ve o, hiçbir zaman, üslup, tarz ya da konu bakımından moda şiir anlayışlarını izlemek gibi bir eğilim göstermedi (Howard Sergeant- Contemporary Poets- Baybars 1997'den, 12).

Hangi edebiyata ait olduğuna dair kendisine yöneltilen bir soruya verdiği yanıt ise, onun kültürlerarasılık konusundaki konumunu belirleyebilecek niteliktedir: İnsana sahip çıkan köken değil dildir. Joseph Conrad'ı Polonyalı bir yazar; Nabakov'u Rus; Tom Stoppard'1 Çek ve Rushdie'yi Hintli olarak sınıflandırmak gülünç olur...Inanıyorum ki beni, 'Kıbrıs doğumlu (veya Kıbrısl-Türk kökenli) Britanyalı şair' olarak tanımlamak en uygunu olacaktır (2014: 126). Baybars'ın kişisel dil evrenindeki üçlü yapının kimi zaman çatışma, kimi zaman “çok dilli belleğinden” kaynaklanan açmazlara yol açtı̆̆ görülür:

Tatll-sert dil belirsizleşiyor, sözcük

sözcükle iç içe.

Kabuk üstünde kabuk, dikilen taht

üstünde bir diken-Yakınım seni yanıma alacă̆ım

söz sözcükten koparken, çok-dilli belleğim (1997: 71).

Şair, bu dizelerde kullanılan "kabuk, taht ve diken" imgeleriyle belleğindeki dillerin çatışma ve iç içeliğini vurgular.

3. Metinlerarasılık: Kültürlerarası edebiyat araştırmalarının biçimsel anlamdaki alt dallarından biri olan metinlararasılık, genel anlamda metnin göndergeselliği ile bağlantılı bir dizi dış etkenin (toplumsal, tarihsel, siyasal vb.koşullar) göz önünde bulundurulmasını gerektirmektedir (Aktulum, 2018: 233-256). Taner Baybars şiirinde metinlerarasılık, anlam zenginliği yaratmanın yanı sıra çeşitli kültürlerin verilerini belirlemek amaçlarıyla da önem kazanmaktadır. Çamaşır Ípi (Baybars, 2007: 179) adlı şiirinde bir halk türküsündeki “Alişimin Gözleri Kara" dizesini olduğu gibi şiirine yerleştiren Baybars, çok etkilendiğini birkaç şiirinde vurguladığı Robinson Crusoe'ye göndermeler yapar (Baybars, 2007: Deniz Kenarında Akşam). Eski Yunan-Roma şairleri dizelerde yer alır (Tepelerde Vicdan Azabı-Baybars, 2007). Mitolojik söylenceler, adlar, motifler aktardıkları ya da anıştırdıkları anlamlarla şiirlerde görülür: Pan (34), Medusa (114), Horatius (149), Hepahistos (162), Ianus (165), Catallus (172). Dante ve Ilahi Komedya'dan sahneler Çölde Sel Baskını adlı şiirde resim görselliğinde dizelere taşınır:

(...)

Dante'nin cehennem görüntüsü bu, Gary Packer'ın çı̆̆lı̆̆l

gırtlak dolusu bir darbe acı üzerinde. Anlayamaz o bunu:

ya bozar ya da kurar heykelleşmiş masumiyetiyle (2007: 203).

Tilki Şairler Arasında başlıklı şiirde hüzünlü ölümleriyle bilinen E. Hemingway, Amerikalı şairlerden Hart Crane ve kurtuluş arayışında kaçışa sığınan J. Berryman'a göndermelerde bulunulur: 
Tetiği çekmeden önce tahmin etmeye çalışlyorum

ne düşündüğünü Hemingway'ın; Hart Crane ne yapardl

atlamadan önce çökseydi üstünde durduğu köprü?

Şu amansız sürüşte dikiz aynası mıydı

John Berryman'ın basıp gitme kararına yol açan? (2007: 205).

Baybars, Gebe Gölgeler adlı kitabının Noel'in 21 Günü başlıklı şiir dizisinin 21'incisinde sıra dışı yaşamı ve şiirleriyle hayatı boyunca âşık olduğu tek kadın olan Lesbia’ya adadığı şiirleri ile tanınan ve genç yaşta ölen Romalı şair Catallus'un dizelerini şiirine montajlar:

“Ah Lesbia, Lesbia'm benim

\section{kimlerin kollarında horluyorsun şimdi"}

yeni yıl yată̆ımda hınçla Catallus okurken ben? (174).

Aynı şiirde İspanyol oyun yazarı Tirse de Molina’nın 1630'da yazdığı El Burlador de Sevilla adlı oyunun ünlü kahramanı Don Juan'ın trajik macerasına gönderme yapılır:

Don Juan'ın birçok fethi oldu ama olmadı hiç sevgilisi.

sahi, kimdi bunu söyleyen? (174).

Şairin farklı amaçlarla şiirlerine konuk ettiği Robinson Crusoe, Bir Bisiklet Yolculuğu şiir dizisinin üçüncüsünde bir kez daha anılır. Dizinin dördüncü şiirinde Sezar'a karşı gelen Brutus'un ordusunda savaşmış bir şair olan Horatius ve çağdaşı Vergilius'un şiirlerine göndermeler yapılır. Roma, Likya kahramanları olan Tityus Amaryllis ve Amyntas'ın adlarına yer verilir. Baybars, Kutsal Kitaplar başlıklı şiirinde çağın ve uygarlığın bilim kaynakları olarak yorumladığı Darwin, Karl Marx, Freud ve Einstein'ın adlarını anar, yapıtlarına açık göndermelerde bulunur; Bebek Kuğurmaları şiirinde Proust'un kişiliği ve yapıtları vasıtasıyla "bebek" imgesinin soyutluğunda "saflığı" sorgular (93). Bir kaç deneme de yaptığı Haiku tarzı şiirin babası olarak bilinen 17. Yüzyıl Japon şairi Başo’nun dizelerini, Sonbahar Yaprakları" adlı şiirinde insan ve doğa arasındaki devinimleri, ruhsal yüzleşmeleri yansıtmak üzere alıntılar. Mitolojinin çirkin olmasına karşın en güzel tanrıçalarla evlenen tanrısı Hephaistos, ironi çağrışımlarının aracı olur:

\section{Tekrarlarken yatakta Noel şarkılarını minik horlamasıyla}

ve bir mum yakarım ben Hephaistos'ça bir ironiyle, gülerek oynarım (162).

Baybars, Tilki ve Beşik Yapanlar adlı şiir kitabının girişinde Fransa'nın doğusunda yaşayan postacı kadın Pascale'ın başından geçen gerçek olayları şiirleştirdiğini "ön not” olarak açıklar. Buna göre zamanın sathiliğinde mekân, gerçek ve daimidir. Kişiler ise gerçekçi olmalarına karşın büyücülük, beddua ve kutsama yollarıyla sürekli biçim değiştirirler. Çok yönlü yaşamlar arasında mücadele eden insanın çaresizliği ve başkaldırmaya muhtaçlığını imleyen kitabın epigrafında ise John Clare'ın (1793-1864) Delilik Iç̧inde Yazılmış Şiirler kitabından bir bölüm yer alır. Aynı kitapta bir Çin atasözü de ayrı bir sayfada alıntı olarak yer alır (204). Karantina şiirinde Kral Lear'e atıf yapılırken (214) “Tilkiye Dönmüş Baküs” 
(216) adlı şiirde mitolojinin ünlü şarap ve bereket tanrısı Baküs'ün (Diyonisos), sembolü olan asma gibi ölüp tekrar dirilmenin; öte yandan da acı ve haz arasındaki devinimlerin sembolü olduğuna dair kapalı gönderimler izlenir:

$(\ldots)$

Kopmuş zincirinden gömleğimin içine kaylyor altın haç.

Uzun zaman geri dönmesini bekledim onun, beklerken

içime boşalttım tek bardaktan, çift yaşam süresini Baküs 'ün..(216).

Geçmişin Falına Bakmak (220) şiirinin dipnotunda şiirde geçen Çin'in en eski fal kitaplarından olan I Ching'de bulunan runik simgelere, gerçekleşmemiş kehanet olgularına açık göndermeler yapılır.

4. Melezlik: Hayatını Kıbrıs, İngiltere ve Fransa'da geçirmiş olan Taner Baybars, kültürel açıdan tipik bir melez kişilik örneğidir. İnsanlık tarihindeki karşılıklı kültürel etkileşimle ortaya çıkan farklı uygulama ve biçimler, küreselleşen dünyanın yeni bir hüviyetini ortaya koymaktadır. Bu konuda yapılmış kılavuz nitelikteki temel çalışmalarda sosyal yapıdaki değişim ve dönüşümlerin evrensel boyutları üzerinde durulmuştur (Burke, P. 2011). Kimlik, kültür ve melezlik kavramları, günümüz toplumlarının temel yapısal özelliğini oluşturma süreçleri arasında yer alır. Öte yandan Baybars'ın özellikle İngiltere'de yaşamaya başladığı ilk dönemlerde Britanya'nın renkli kültürel peyzajı, buradaki farklı kültürlerin birlikteliği, şairin eserlerinde çokkültürlülüğün çokça yer etmesini sağlamıştır (Gelfand vd 2008-Kültürlerarası Psikoloji'den s.344) Bireysel melezleşme her ne kadar toplumlararası devinimlerden soyutlanamazsa da, tekile indirgenen melezleşmenin temel paradigmaları arasında dil ve uzam farklılık ya da varsıllıkları ön planda gelmektedir (Holton, 2013). Dildeki melezlenme terimini ilk kullanan dilbilimci Mikhail Bakhtin, çok sesli anlatıcılığın etki ve gücüne işaret etmiştir (Yıldız, 2014: 35). Bu bağlamda Taner Baybars'ın Douanier Rousseau başlıklı şiiri, çokkültürlü etmenlerin dilde yarattığı melezleşmeye bir örnektir:

We left Dieppe in the brightness of sun

and found Newhaven as much sunned and coy

and tiptoeing through the Customs in the car

we stopped in front of a sentry who,

lifting the bonnet with his little finger,

laughed: monsieur-dame, sortez. But Why?

What about this cake os sun, smell of fruit

and this little bit of French cloud in here? (1997: 90).

Kültürlerarası Psikoloji öğretisinde entegrasyon ve çokkültürlülük kavramları hem kültürlerin kimliklerinin ve kültürel özelliklerinin devamlılığını öngörür hem de geniş ölçekli çoğul toplumda katılımı gerektiren tutumu ön plana çıkarır (Abayhan, 2015). 
Kültürel melezlik eksenindeki bu kuramsal çerçevede Taner Baybars, tipik bir melez/hibrid kültür oluşumunun merkezinde duran bir şair görüntüsü vermektedir. Göç ettiği İngiltere'de anadilin şiirsel sermayesinin üstüne kurduğu İngiliz ve Fransız dilleri, Baybars’ta salt sözsel ifade/anlatım odağından değil, düşünce, bakış açısı ve yorumlama açılarından da geniş bir spektrum yaratmıştır. Bu bağlamda şairin konumu ve önemi hakkında Enis Batur'un Kırk yılda bir Türkçe şiir yazdl, ama kırk yıldır Türkiye'de yazılan şiirlerin çoğundan daha iyisini yazdı değerlendirmesi dikkat çekicidir (Baybars, 1997: 13). Evrensel kültürün mitoloji verilerinden, farklı kaynakların birikimlerine girebilmiş olan Baybars, yukarıdaki maddelerde örneklendirilmeye çalışılan başlıklarda görüldüğü üzere; Akdeniz türkülerinden pastoral söylemlere, klasikleşmiş diyebileceğimiz dünya edebiyatlarının ışıltılı evrenlerine, tinsel duyuş, coşku ve spiritüel sarmallarla oluşan kendine has bir melez/hibrid şiir dünyası yaratmıştır.

\section{Sonuç}

Karşılaştırmalı edebiyat araştırmalarının bir alt disiplini olan kültürlerarası edebiyat, günümüzde edebî ürünlerin algılanması ve özümlenmesinde eserlerdeki çok boyutlu ilişki ve etkileşimlerin incelenmesine olanak sağlamaktadır. Bu kuramla, farklı odaklardaki veriler ele alındığından kuşaklar, uluslar ve coğrafyalar arasında köprüler kurulabilmekte; kültürler arasındaki ilişki, çelişki ve etkileşimlerden beslenen edebî eserler ve şahsiyetlerin incelenmesinde somut yararlar elde edilebilmektedir.

Kültürlerası edebiyat, din, dil ve uygarlıklar arası diyalogların edebî ürünlere yansıma biçimleri ve "öteki” kavramını çözümleyici niteliğiyle yeryüzünün kaotik yapısında anlayışlılık ve paylaşım inceliklerini yeniden gündeme getirme çabası içindedir. Bu anlayış bağlamında ele alınacak sanatçıların çokkültürlülük atmosferlerini özümlemiş; bu bağlamdaki birikimlerini yapıtlarına yansıtmış olmaları başat özelliktir. Mitolojiden, tarihe, antropolojiden, toplumbilime, psikolojiden dilbilime uzanan veri analizleri ve bunların edebî ürünlere taşınma süreçleri, çokkültürlü edebî ürünün niteliklerini belirlemektedir.

$\mathrm{Bu}$ araştırmada içerik açısından kültürel çatışmalar ve kültürel karşılaşmalar; biçimsel anlamda da tür adaptasyonları, dil çeşitliliği, metinlerarasılık ve melezlik temel ölçütleri, Taner Baybars'ın şiirleri üzerinde yöntemsel bir uygulamayla irdelenmiştir. Eserleri hakkında sınırlı araştırma yapılan Taner Baybars, Ortadoğu, Akdeniz temelindeki kültürlenme sürecini, Britanya, Fransa topraklarında çeşitlendirirken Türkçenin şiirsel yapısını İngilizce ve Fransızcanın geniş anlatım kaynakları ile biçimlendirmiş bir şairdir. Taner Baybars, temeli Ortadoğu-Akdeniz kültürüne dayalı; sonrasında Anglo-sakson kültürünü özümlemiş bir şair olarak yerelden evrenselliğe doğru bir genişlemenin odağında bulunmaktadır. Ondaki bireysel varoluşun yetişkinlikte farklı coğrafyalardaki uyanışı ise çocukluğunun geçtiği Kıbrıs'ın farklı dil ve dinlerin bir arada bulunduğu çokkültürlü yapısını gündeme getirmektedir.

Baybars'ın ilk dönem şiirlerinde Mağusa'dan Üsküdar'a, İstanbul'a uzanan coğrafi yayılımla boy gösteren yerel kültür, Gülten şiirinde Cypre'deki kınalı parmaklar, Cypres'in sateni gibi imajlarla yansıtılırken genç yaşta gerçekleşen göç, yeni coğrafya, yöntemin ilk 
basamakları olan kültürel çatışma ve karşılaşmaların da sahnesi olur. Her ne kadar kozmopolit yapısından söz edilse de Akdeniz kültürünün tipik özelliklerini taşıyan Kıbrıs’tan İngiltere merkezli Batı kültürüne geçiş, ardından şairin Fransa tecrübesi, değinilen çatışma ve karşılaşmaların boyutlarını genişletir. Kültürel çatışmanın temelini biçimlendiren semboller, kahramanlar, ritüel ve değerler, Baybars şiirinin yeni ırasını ortaya koyar. Dildeki Türkçe, İngilizce ve Fransızca olmak üzere üçlü yapı, bu dillere ait kültürel verilerin zenginliği, Baybars şiirinin anlatım odaklarındaki özgün yapıyı yaratmıştır. Şairin yaşadığı yılların Avrupa genelindeki kültürel geçişkenliklerin yoğunlaştığı dönemlere rastlaması, şiirlerde çokkültürlü metafor ve imge zenginlikleri, metinlerarasılık, yan anlam, yakın ve uzak çağrışımların sergilenmesinde etken olmuştur. Mitolojik verilerden, eski ve güncel edebiyattan sanat dünyasının etkili isimlerine/eserlerine, bilim insanlarına, kutsal kişi ve değerlere uzanan geniş etkileşim alanının merkezinde duran Taner Baybars, günlük yaşamın rutin çarklarında da farklı kültürel unsurları dizelerine aktarmış, kültür ve kimlik ekseninde dili öne çıkararak kültürlerarası bir şiir dünyası yaratmıştır.

İnsancıl bakış açısını göz ardı etmeyen Baybars, insanlık tarihinin biçimlendiği coğrafyaların kültürüyle süzülmüş şiirinde yer alan zengin izlekler ve yetkin anlatım ürünleriyle evrensel bir "dünya şairi” kimliğine ulaşmıştır.

\section{Notlar}

1 Taner Baybars, Seçme Şiirler, s. 12

2 Bu çalı̧̧malar içinde Meral Demiryürek'in Kıbrıs 'tan Britanya'ya Uzanan Bir Ada İnsanı: Taner Baybars adlı makalesinde (Kıbrıs Araştırmaları ve incelemeleri Dergisi, 1-2 Ocak 2018a s. 79-94) Baybars'ın genellikle İngilizce ve ayrıca Fransızca şiirler yazarak koloniyel bir özellik kazandığı vurgulanarak, makalenin Hitit Üniversitesi FEF 19001. 14. 002 kodlu "Taner Baybars Hayatt-Sanatı-Eserleri" başlıklı bitmiş projenin verilerinden yararlanılarak yazıldığı vurgulanır.

3 M. Demiryürek, Taner Baybars-Osman Türkay-Talat Halman Mektuplaşmaları Bağlamında Türk Edebiyatı (III. Uluslararası KIBATEK Kıbrıs Türk Edebiyatı ve Edebiyatçıları Sempozyumu, 2018b) çalışmasında Osman Türkay'ın yanı sıra Taner Baybars'ın da yurt dışında Türk edebiyatının Batı ülkelerinde tanıtılması için çabalar sergilediğini açıklar.

4 Meral Demiryürek'in İngiltere'de Bir Kıbrıslı Türk Yazar Taner Baybars ve Çevirileri, (XI. Uluslararası Büyük Türk Dili Kurultayı, 2016) adlı bildirisinde ise şairin eserlerini oluşturması sürecinde Kıbrıs etkileri ele alınır.

5 T. Baybars hakkında bir başka yazı, Emel Kaya’ya aittir. Kaya, 13 Mayıs 2017 tarihli Yeni Düzen gazetesinde yer alan Yaşamın Sinir Uçlarında Taner Baybars Şiiri başlıklı çalışmasında "pek çok temayı, insanı irdelemek, insanın yeryüzündeki hacmini, yaşama anlam katma çabasını kavramak için kullanan şairin tematik çeşitlilik, anlam katmanları oluşturulmuş incelikli, dolaylı, yer yer ironik bir dilsel zenginlikle” dikkat çektiğini vurgular.

\section{Kaynaklar}

Abayhan, Y. (2015). Kültürlerarası ilişkiler. (Kültürlerarası psikoloji ortak kitabında), İstanbul: Nobel. Aktulum, K. (2018). Metinlerarasılık görüngüsünde gerçeklik ya da metnin göndergeselliği. Bilig. Türk Dünyası Sosyal Bilimler Dergisi, 85: 233-256.

Aylanç, M. (2011). Kıbrıs Türk romanında göç. İstanbul, TC Marmara Üniversitesi Türkiyat Araştırmaları Enstitüsü Türk Dili ve Edebiyatı Anabilim Dalı Yeni Türk Edebiyatı Bilim Dalı,Yayımlanmamış Doktora Tezi.

Baybars, T. (1954). Mendilin ucundakiler. (Tilki ile Çobanaldatan içinde). Lefkoşa: Çardak. 
Baybars, T. (1997). Seçme şiirler: 1947- 1997, İstanbul: Yapı Kredi Yay.

Baybars, T. (1997). Uzak ülke: Bir Kıbrıs çocukluğu. B. Ö. Düzgören (Çev.). İstanbul: Yapı Kredi.

Baybars, T. (2007). Tilki ile çoban aldatan-Toplu şiirler (1951-2001). G. Korkmazel (Çev.) İstanbul: Yap1 Kredi.

Baybars, T. (2014). İspinozlar. Lefkoşa: Işık Kitabevi.

Benedict, R. (1996). Krizantem ve kılıç-Japon kültür önekleri. İstanbul: İşbankası.

Berdnikov, G.N. (1989). Istoria vsemirnoi literatury (A History of World Literature). Moscow: Nauka.

Berry, J. W. (2015). Kültürlerası psikoloji-Araştırma ve uygulamalar. L. P. Tosun (Çev. Ed.) İstanbul: Nobel.

Bozkurt, N. (2004). 20. yüzyll düşünce akımları. İstanbul: Morpa Kültür.

Burke, P. (2011). Kültürel melezlik. M. Topal (Çev.). İstanbul: Asur.

Cengiz, S. (2014). İmparatorluktan ulus-devlete çokkültürlü kimliklerin ifade alanı: Kültürlerarası edebiyat. Akademik Sosyal Araştırmalar Dergisi, 6:50-57.

Çakır, M .(2010). Kültürlerarası iletişimin bir yönü: Özün ötekileştirilerek yabancılaştırılması. Anatolia Turizm Araştırmaları Dergisi, 1: 75-84.

Demiryürek, M. (2016). İngiltere'de bir Kıbrıslı Türk yazar Taner Baybars ve çevirileri. XI. Uluslararası Büyük Türk Dili Kurultayı.

Demiryürek, M. (2018a). Kıbrıs'tan Britanya'ya uzanan bir ada insanı: Taner Baybars. Kıbrıs Araştırmalart ve Incelemeleri Dergisi, 1-2: 79-94.

Demiryürek, M. (2018b). Taner Baybars-Osman Türkay-Talat Halman mektuplaşmaları bağlamında Türk Edebiyatı. III. Uluslararası KIBATEK Kıbrıs Türk Edebiyatı ve Edebiyatçıları Sempozyumu.

Durisin, D. (1989). Theory of interliterary process. Bratislava: Obzor.

Galik, M. (2000). Interliterariness as a concept in comparative literature. Comparative Literature and Culture. 4:1-7.

Gelfand, M., L., M. Erez, and Z.Aycan, (2007). Cross-cultural organizational behavior. Annual Review of Psychology, 58: 479-514.

Gallagher, S. E. and T. Savage (2013). Cross-cultural analysis in online community research: A literature review. Computers in Human Behavior, 29: 1028-1038.

Holton, R. (2013). Küreselleşmenin kültürel sonuçları. K. Karaman (Çev.). Sosyoloji Konferansları Dergisi, 47: 59-75.

Kartarı, A. (2001). Farklılıklarla yaşamak: Kültürlerarası iletişim, Ankara: Ürün.

Kaya, E. (2017). Yaşamın sinir uçlarında Taner Baybars şiiri. Yeni Düzen Gazetesi, Lefkoşa.

Matajc, V. (2009). Literariness as interliterariness, cosmopolitan 'Author' and 'Interpreter'. Primerjalna Knjizevnost , 32: 213-232.

Mecklenburg N. (2008). Das mädchen aus der fremde-Germanistik als interkulturelle Literaturwissenschaft. Münih: Iudicium.

Mignon, L. (2009). Ana metne taşınan dipnotlar-Türk edebiyatı ve kültürlerarasıllı üzerine yazılar. İstanbul: İletişim.

Roche, Jörg. (2001). Interkulturelle sprach didaktik: Eine Einführung. Tübingen: Günter Narr Verlag.

Tidball, Derek (2018). Kutsallık; Tanrı'nın şaheserinin onarılması. U. Demirgil (Çev.). İstanbul: Haberci Basin.

Ulusoy, H. Ö. (2017). Kültürlerarasılık, çokkültürlülük ve etnisite: Eskişehir'deki Çerkeslerin kültürlerarası iletişim pratikleri. Akdeniz İletişim Dergisi, 27: 165-181. 
Venera R. A., Gulfia R. Gainullinab, Oksana V. Shemshurenko (2016). The interliterary dialogues' heuristic potential on the lessons of the Russian literature in the mulyiethnic environment. IFTE 2016: 2nd International Forum on Teacher Education.

Von Zimmerman, C. (2006). Kulturthema migration und interkulturelles schreiben. Recherces Germaniques. ed. C. Maillard, Revue Annuelle, 3:7-25.

Yaşın, M. (2005). Kıbrıs şiiri antolojisi. İstanbul: Adam.

Yaşın, N. (2017). Taner Baybars'ın Babil kulesi. Yeni Düzen Gazetesi. Lefkoşa.

Yıldız, T. (2014). Saussure'den Bakhtin'e dil-kültür ilişkisi: Tümü kapsayıcı olgu. İdil, 3.

Wellek, R. (1963). The crisis of comparative literature. Concepts of criticism. Yale UP. 282-95.

\section{Elektronik kaynaklar}

Kappler, M. (2009). Remembering a childhood in Cyprus: Taner Baybars' "smellscape" and multiculturalism in his autobiography, plucked in a far-off land" in Turkish literature and cultural memory. Multiculturalism as a Literary Theme after 1980. (Editor: C. Dufft). https://core.ac.uk/download/ pdf/41126075.pdf. (erişim 09.08.2019).

Karahasan, H. (2004 ). The politics of national identity and the idea of 'home' in Taner Baybars' 'Letter to homeland' and Mahmoud Darwish's 'A gentle rain in a distant autumn' and '1dentity card”, www.researchgate.com/file:///C:/Users/CIU/Downloads/JCS2004-Paper\%20(1).pdf(erişim 18.02.2019) 